\title{
Affective Dissent
}

\author{
Stephen Healy \\ University of New South Wales.
}

\begin{abstract}
'there is at least one invariant that means that that the population taken as a whole has one and only one
\end{abstract} mainspring of action. This is desire...' (Foucault 2007, p. 72).

'The ability of affect to produce an economic effect more swiftly and surely than economics itself means that affect is a real condition, an intrinsic variable of the late capitalist system, as infrastructural as a factory'

(Massumi 2002a, p. 45).

'The status quo is entrenched not only through a common economic logic, but also a common sensorium,
which we neglect to our detriment. Neoliberalism entrains us to experience certain emotions over others,
suggests rules for their expression, and even tries to define what one is "allowed” to feel for. These
everyday flows of feeling —-from bodily intensities of relation (affect) to their narrativized accounts
(emotion)—-habituate us to the cadence of neoliberal subjectivity' (Jensen 2011).

\begin{abstract}
This article identifies a form of corporeally enacted affective bio-politics more intimately engrained than that identified in recent work emphasising the affective qualities of activism and labour. While these latter reinforce and bolster existing analyses through highlighting affective concerns, the affective bio-politics identified here suggests that neoliberalism is significantly maintained through, what have generally been, unrecognised affective means. While this affective regulation can only ever be partial and imprecise, its unrecognised, and thus implicitly concealed, character lends it a particular strength and cogency. Illuminating the mechanisms through which such affective regulatory modulation is achieved thus has a powerful potential to clarify further opportunities to disrupt and counter neoliberalism. This account juxtaposes an analysis of affective bio-politics with existing analyses of the affective, and performative, dimensions to activist politics, in order to facilitate the identification of specific opportunities for further affective contestationary strategies.
\end{abstract}

Much has been written about the affective dimensions of activism and dissent (Hynes, Sharpe \& Fagan 2007; Hynes, Sharpe \& Greg2008; Hynes \& Sharpe, 2010), of labour (Hardt \& Negri, 2000; 2004) and even of politics more broadly (Protevi 2009) although affective bio-politics per se has received only limited attention (but see: Anderson 2012). This account endeavours to address this deficit in order to suggest strategies that might be harnessed to counter the affective regulation sustaining neoliberalism, both within and beyond activism. After a brief introduction to the analytic vocabulary employed in this article the rest of this section presents a brief review of recent work addressing the intersection of affect and politics. The subsequent section further 
delineates the specific perspective on affective bio-politics adopted here. This is followed by a discussion of recent accounts of affective politics and activism that informs an ensuing discussion of further, more focused, affective contestationary strategies, which prefaces a short concluding section.

Affect, as understood here, is distinguished from the, typically, subjectively conceived notions of emotion and feeling, with which it is associated, by its dependence 'on a sense of push in the world' (Thrift 2004, p. 64). ${ }^{1}$ This might be the 'pull and push of place' (Duff 2010, p. 893), or of bodies or of other entities in those places. Affect is, thus, relationally constituted and 'does not reside in an object or a body, but surfaces from somewhere in-between' (Adey 2008, p. 439), emerging 'as a relation between bodies, objects, and technologies' (Bissell 2010, p. 272). Affects, however, affect in the sense of 'pushing' such relationships in some directions rather than others and while they may, as Brennan (2004) argues, have a biological basis affects are, and have been, widely employed to promote specific outcomes. Architecture provides an exemplary example (e.g. Allen 2006; Adey 2008; Kraftl \& Adey 2008) that Kraftl and Adey argue can both 'engender...new fields of virtual potential...[and]...simultaneously delimit, design(ate), and demarcate strict performative and often moral possibilities' (2008, p. 226). While Thrift's 'microbiopolitics of the subliminal' (2004, p. 68) is suggestive of mechanisms that might help explain how the kinds of 'possibilities' depicted by Kraftl \& Adey (2008) are accomplished, broader ranging discussions of the dynamics of affective bio-politics are hard to come by.

Anderson (2012) addresses this lacuna in an analysis that emphasises macro-scale dimensions to affective bio-politics, notably 'state-phobia' a term that Foucault (2008, p. 76) coins for antistatism while, echoing Thrift (2004), remaining optimistic regarding the 'political and ethical promise' of 'work on the dynamics of affective life' (Anderson 2012, p. 29). The author (Healy 2012) has, however, problematized this 'promise' by arguing that 'affective life is imbricated in the working out of the neoliberal problem of how to organise life according to the market' (Anderson 2012, p. 40) more thoroughly and intimately than Anderson’s emphasis upon macro-

\footnotetext{
${ }^{1}$ While there is no consensus in the literature, those using the language of emotion commonly concede traditional distinctions between it and 'rationality' and privilege cognitive criteria, while those using the language of affect do neither of these things. Scholars such as Demasio (e.g. 2003) and Maturana and Varela (e.g. 1992) illuminate the problematic character of traditional thinking, while Pile (2010) is illustrative of recent debate regarding these differences.
} 
scale affective phenomena suggests. This more pervasive and intimate perspective on affective bio-politics is further pursued here in order to explore and illuminate its contestationary potential. For while a more ubiquitous perspective on affective bio-politics implies further challenges for contestationary politics, the delineation of these dimensions to neoliberal government also has the potential to illuminate further opportunities, and means, to counter neoliberalism. As a first step to identifying these opportunities, the rest of this opening section briefly surveys recent work on the intersection of affect and politics.

Among the best-known invocations of the affective character of politics is the notion of affective labour that arose in Autonomous Marxist critiques of the 1970s and has become an important aspect of Hardt and Negri's recent work (2000; 2004). For Hardt and Negri affective labour is an aspect of immaterial labour focused upon 'human contact and interaction' and which they illustrate through the examples of the health services and entertainment industry (2000, p. 292). Although they highlight the somatic and corporeal aspects of affect their perspective is quite unlike that adopted here. Ruddick (2010) gets to the crux of this difference, succinctly showing how for Hardt and Negri affect becomes little more than a 'corporeal motivation, a push and pull factor' (2010, p. 33) in 'a neo-Leninist determination in which affective labour plays the role of vanguard' (p. 32). Protevi (2009) is far more ambitious, developing a 'political physiology' concerned with how 'bodies, minds and social settings are intricately and intimately linked' (p. xi). However, while indebted to Deleuze and Guattari, Protevi adopts a cognitive perspective on affect such that, regardless of the complexity and sophistication of his analytic framework, affect is reduced to little more than the emotional content of his case studies (specifically love, rage and fear), far removed from the non-cognitive relational interpretation of affect adopted here.

Activism provides a major focus of work on the affective dimensions of politics. While some have focused on the emotional and/or affective content of activism (e.g. Sullivan 2005), of more relevance here are accounts of the political, and sometimes transformative, impacts of humour, performance and other activist interventions (Hynes, Sharpe \& Fagen 2007; Hynes, Sharpe \& Greg 2008). Indeed this transformative potential has informed and inspired specific forms of activism exemplified by groups such as the 'Yes Men' (Hynes, Sharpe \& Fagen 2007), the 
'Clown Army', ${ }^{2}$ and the 'Laboratory of Insurrectionary Imagination'. Much of the flavour of these is caught by the latter that 'merges art and life, creativity and resistance, proposition and opposition ... treat[ing] insurrection as an art and art as a means of preparing for the coming insurrection'. ${ }^{3}$ While these might simply be conceived in terms of the well-understood power of the performative and, more broadly, affective dimensions of activism, ${ }^{4}$ McDonald (2006) argues that 'experience movements' of this character are now prevalent and of more fundamental significance. For McDonald (2006) the corporeally enacted experiential 'grammars of action', characteristic of recent activism, signal a rupture with the instrumental logic of the isolated individual so central to neoliberal modernity. The leading green political theorist Douglas Torgeson echoes this in arguing that a performative style of debate and humour provide the green movement with a powerful means to transform politics as usual (1999). Such work, and various of the forms of resistance it informs, and that inform it, highlight the potential of affectively infused forms of activist ‘doing' (McDonald 2006) to interrogate, usurp and potentially transform conventional politics.

Others have investigated the affective registers through which politics as usual operates, the ways these act to maintain and sustain neoliberal subjectivities and behaviours, and the opportunities that might be generated by elucidating these generally unacknowledged affective ecologies. Much of this latter work, particularly the perspective on affective bio-politics adopted here, stems from post-structural analyses of affective life that, most typically, derive from a Deleuzian reading of Spinoza. Massumi (2002), Thrift (2004) and Cultural Geographers working in the Non-Representational tradition (e.g. Anderson 2009; 2012; Bissell 2010; Duff 2010), pioneered by Thrift, provide key sources drawn upon here. While it has been long recognized that affective life is political and that power operates in affective registers (e.g. Massumi 2002a; Thrift 2004), the specifics of affective bio-politics have received only scant attention. Anderson (2012) presents a seminal analysis that, building on Foucault's contention that 'homo economicus...becomes the correlate of a governmentality which will act on the environment and

\footnotetext{
${ }^{2}$ http://www.rebelclown.net/clogs/; accessed 29/1/13. See: http://birca.blogspot.com.au/ (accessed 29/1/13), for the down-under offshoot.

${ }^{3}$ http://labofii.wordpress.com/; accessed 29/1/13.

${ }^{4}$ Greenpeace, for example, have long has this down to a fine art with the, commonly consultant produced, campaign report targeting relevant government ministers issued the same day that a dramatic stunt highlighting key campaign arguments hits the evening TV news and, when successful, headlines them.
} 
systematically modify its variables' (2008, p. 271), proposes 'environmentalities' as a key mechanism. ${ }^{5}$ These 'work through systematic modifications of the 'environment' within which an action occurs, rather than directly on the body's capabilities' (Anderson 2012, p. 39), a notion that will be further explored below. The 'normative blind spots' (Barnett 2009) that have been identified in this work will also be briefly addressed.

\section{Affective Bio-politics}

Work in the tradition discussed in the latter section above has identified many affective dimensions to politics. ${ }^{6}$ Thrift, for example, notes: 'the marshalling of aggression through various forms of military trainings' (2004, p. 64); 'a mediatisation of politics' that 'tends to foreground emotion...concentrat[ing] on key affective sites such as the face or voice' (p. 65); 'new forms of calculation in sensory registers,' involving mapping what bodies can and cannot do gesturally, conversationally and so on, at all physical and temporal scales (pp. 66-67); and 'the careful design of urban space to produce political response' (p. 67). While some of these, notably 'mediatisation' and 'new forms of calculation,' might be regarded as novel, 'the marshalling of aggression' and political character of spatial design have long-standing historical antecedents (notwithstanding a clear scale up in the scale and sophistication of such endeavours in recent centuries). Similarly, while Thrift acknowledges 'the greater and greater engineering of affect' over time (2004, p. 64) his focus upon developing a 'microbiopolitics of the subliminal' (2004, p. 68), inspired in large part by Connolly’s 'neuropolitics’ (2002), emphasises specifically contemporary manifestations of the 'engineering of affect', such as 'mediatisation,' rather than other longer standing instances of such 'engineering.' It is these latter that are of particular concern here.

Although Anderson's (2012) aims resonate with those of this account his emphasis upon 'statephobia,' briefly discussed above, effectively discounts what may be more fundamental aspects of the 'engineering of affect'. Anderson aims to illuminate how 'affective relations and capacities are object-targets for discipline, bio-politics, security and environmentality’ (2012, p. 28), and

\footnotetext{
${ }^{5}$ This differs from the natural environment focused usage of this term by, notably, Luke (1995) and Agrawal (2005) but is used in precisely this sense by Massumi (2005, p. 12, n.9) in a translation that Foucault (2008, p. 261) renders as 'environmentalism.' See also Massumi (2009; 2010, p. 68 n. 12).

${ }^{6}$ Distinct from how others have identified the way emotion/feeling can motivate and/or sustain movements (e.g. Gould 2002).
} 
finds that homo economicus is 'an 'object-target' that actualises and expresses state-phobia' (38). However, more fundamental affective influences are at work on homo economicus. As Anderson notes, homo economicus 'is always-already an affective subject,' particularly in terms 'of desire and disinterested interests’ (2012, p. 38). Regarding the latter he notes Hirschman’s (1977/1997) pioneering work that showed how 'the hybrid "interests” were first conceptualised as a counterweight to the destructiveness of passions and the ineffectiveness of reason' (Anderson 2012, p. 38). Anderson does not, though, discuss how Hirschman went on to note that the outcome of the success of this conceptualization, in the form of contemporary economics, ${ }^{7}$ was 'to repress certain human drives and proclivities and to fashion a less multifaceted, less unpredictable, and more “one dimensional” human personality.' With the result that once 'capitalism was triumphant and "passions” seemed indeed to be restrained and perhaps even extinguished...the new world seemed to lack nobility, grandeur, mystery, and, above all, passion’ (Hirschman 1977/1997, p. 132). In other words, according to Hirschman (1977/1997), the regulation of 'certain human drives and proclivities' are a key to the establishment and maintenance of homo economicus. The 'environmentalities' this required, attuned to achieving the hegemony of 'a less multifaceted, less unpredictable, and more “one dimensional” human personality’ type, provide a focus for the account below.

The author's analysis of the affective atmosphere of contemporary retail spaces (Healy 2012) illuminates the 'environmentalities' that homo economicus requires, while McDonald's (2006) emphasis on the embodied and experiential character of contemporary activism, further discussed in the ensuing sections, suggests how contemporary activism might provide a rupture with the narrowly instrumental neoliberal personality characteristic of modernity. Much of the character of how the hegemony of this personality type is achieved and maintained can be gleaned from McDonald's repeated insistence that the focus of much recent social movement theory upon the symbolic mediation of identity, via for example 'interests', simply reproduces an out-dated paradigm (2006, pp.211-214). Healy (2012) shows how much of the power of this paradigm, in addition to its assimilation in bodies of theory, has rested upon the way it engages

\footnotetext{
${ }^{7}$ Hirschman's (1777/1997) argument is somewhat more nuanced than this with a key finding being that Adam Smith's innovation was to conflate 'the passions and the interests' via the finding that a desire for material advancement was the predominant factor driving humanity a view that, from this time, became institutionalized in the form of contemporary economics.
} 
affective domains, such as those of the senses, while at the same time denying them explicit legitimacy.

This significance of sensate phenomena to neoliberalism is highlighted by the sensibility of physical comfort, which emerged in tandem with the eighteenth century consumer revolution (Crowley 2001). This sensibility directly informs the ambient form of thermal comfort generated by air-conditioning that provides a component of the affective engineering of contemporary retail spaces (Healy 2012). The affective atmosphere of these spaces facilitates the involuntary, but regulatively enacted, subdual of the auto-affective attention of consumers making them more vulnerable to stimuli specifically designed to encourage shopping. This subliminal affectively mediated mechanism is, thus, a form of sensate, and generally opaque, bio-politics and likely illustrative of 'environmentalities' more broadly. The close links between these retail spaces and automobility is highly suggestive of this and underlined by Sheller's observation that automobility is 'implicated in a deep context of affective and embodied relations between people, machines and spaces of mobility and dwelling, in which emotions and the senses play a key part' (2004, p. 221). Healy (2012) argues that such affectively engineered relationships are likely a pervasive feature of contemporary neo-liberal environments and behaviours.

\section{Affect and Contestationary Activism}

While, as briefly outlined above, much work in this area has focused upon the affective, performative, humorous and/or experiential content of activism, a variety of recent work has started to interrogate the dynamics of these and how they may intersect, or be brought into intersection, with the affective dynamics of capitalism. Hynes \& Sharpe (2010), focusing on the anti-globalisation movement, suggest that understanding the movement 'at the level of ideals and ideology' (2009, p. 1) overlooks the affective dimensions to these protests and, following Spinoza, caution that ' $[\mathrm{b}] \mathrm{y}$ assuming ourselves to be masters of our bodies and their passions, knowledge of the real order of causes eludes us' (2009, p. 7). They highlight Spinoza's distinction between affectio (affection) that describes a determinable state at a particular moment and affectus (affect), which describes a passage between states, and the related increase or decrease in the ability of the bodies thus affected to act. This leads them to emphasise how the corporeal reality of protest can give substance to the potential of an alternative politics through 
reflecting and expressing alternative ideals rather than simply enunciating pre-existing ones. However, while Hynes \& Sharpe (2010) underline the potential of protest to engender positive affects they say little about how such an affective politics might engage the more 'infrastructural' ways affective forces are harnessed to support and maintain neoliberalism (Massumi 2002a, p. 45).

McManus (2011) sets out from a recognition of 'the pervasiveness of the ways in which contemporary politics mobilizes, assembles (and dissembles) affective states into anticipatory and agential formations' to develop a 'critical understanding of the dynamics of affective politics generally, and of hope and fear in particular.' Emphasising the agential capacity of affect she sets out to identify 'manoeuvres of affective ambivalence; that is to say...the ways affects can orient or dispose very different agential possibilities'. She finds that '[o]ne way of restructuring fearaffect...is by intervening in the feedback loops through which fear is stabilized. This might involve turning the technologies that are central to the production of fear against themselves: when protesters use surveillance technologies against police, for instance'. Or, as she later restates, 'the human and non-human technologies through which fear-affects circulate can be restructured, made to resonate differently', a matter further explored in the following section. Ultimately, though, her emphasis upon illuminating “"wriggle room” against forms of affective determinism’ (Massumi 2002b, p. 214) while also, perhaps somewhat incongruously, highlighting the autonomy of affect (Massumi 2002a), constrain her to a focus upon strategies of ambivalence and indeterminacy. She does, however, further suggest that 'visceral experimentation with our everyday sensorium can have effects upon the “tone” of the age,' a matter taken up by Jensen below and that, in the following section, I will argue, points to various, generally overlooked, means of countering ‘infrastructural’ affective influences.

Jensen points to how the sensorium erected by neoliberalism helps entrench the status quo through 'entrain[ing] us to experience certain emotions over others, suggest[ing] rules for their expression, and even $\operatorname{tr}[$ ying] to define what one is "allowed" to feel for...habituat[ing] us to the cadence of neoliberal subjectivity' (2011). He specifically 
'advance[s] the common sensorium as a name and frame for exploring how the animating forces of affect and emotion are collectively configured to achieve...normalizing structures...in which cultures reproduce themselves by encouraging the experience of particular emotions in particular ways, sanctioning certain expressions of those emotions while disciplining others' (http://timjensen.net/2012/06/dissertation/; accessed 5/1/13).

He is also sensitive, echoing a key argument of this account, to how:

'Tactics that leverage the features and formations of existing terrain to their advantage can be applied to the emotional and affective terrain created by neoliberalism' (Jensen 2011).

Jensen, however, and perhaps reflecting the constraints inherent in his emphasis upon emotion, primarily limits his analysis to matters of rhetoric and discourse.

Sensoria, though, as the author demonstrates through the example of contemporary retail environments (Healy 2012), also involve a:

'material grammar of the encounter of bodies, that traverse and transform those bodies, and galvanize and energize (or 'diminish') the subject's capacity for acting within its world’ (McManus 2011).

This 'material grammar' reading of how contemporary sensoria, such as malls, 'habituate us to the cadence of neoliberal subjectivity'. Jensen (2011) suggests potential interventions to reframe and reconstitute neoliberal subjectivities and behaviours. In addition McDonald (2006) identifies new 'grammars of experience and action' in contemporary activism that challenge the impoverished neoliberal circumscription of 'certain human drives and proclivities' (Hirschman 1977/1997, p. 132). So '[t]actics that lever...the emotional and affective terrain created by neoliberalism' (Jensen 2011) might draw upon both 'material grammars' involving many other than human things, such as air conditioning systems (Healy 2010; 2012), and the new 'grammars of experience and action' at work in contemporary activism (McDonald 2006). Some of the potential avenues for affective dissent these suggest are explored below. 


\section{Further Avenues for Affective Dissent}

While the 'emotional and affective terrain' of neoliberalism remains relatively poorly understood some indication of potential further avenues for dissent can be gleaned from examining some more unusual, and emergent, avenues explored to date. The 'Yes Men'8 strategy of impersonating spokespeople for corporations and a variety of other mainstream neoliberal organisations at high profile meetings, usually to throw light on their politics through tactics such as reversing policy platforms, is a good example. Many analogous forms of, what are commonly labelled 'culture jamming', similarly utilize satire and irony to play up the ethically and politically dubious content of, in particular, media culture and advertising. Other groups, such as 'Reclaim the Streets', ${ }^{9}$ apply an analogous logic to specific targets, in this case automobility. Notable, in recent years has been the emergence of a range of civil society groups, very much in response to a perception that politics as usual, both mainstream and oppositional, is proving inadequate for purpose, commonly motivated by environmental challenges. The Transitions Towns movement ${ }^{10}$ provides an excellent large-scale coordinated example, with the parallel proliferation of local Climate Action Groups ${ }^{11}$ a good illustration of the grass roots demand for such initiatives. More broadly, the recent exponential, and incredibly rapid, spread of 'occupy' movement mobilisations ${ }^{12}$ illustrates the depth of appetite for fundamental change. Another indication of both this 'appetite' and disillusionment with existing avenues and means for change is the way the artistic community is increasingly engaging with political alternatives. While many simply echo existing discourses, such as 'sustainability,' others are bringing an artistic sensibility to bear on alternatives because, for example, they 'have stopped believing the stories our civilisation tells itself' (http://dark-mountain.net/about/faqs/; accessed 12/2/13).

While exceedingly diverse, the examples given above tend to diverge from more traditional activism in terms of the means, methods and/or sites through which they express and/or accomplish dissent. Generally more focused by process and means, and on giving substance to an alternative politics, they target: neoliberal institutions directly (i.e. the 'Yes Men');

\footnotetext{
${ }^{8}$ http://theyesmen.org/. The idea of using this as a basis for identifying further contestationary opportunities is the inspiration for: http://yeslab.org/.

${ }^{9}$ http://criticalmass.wikia.com/wiki/Reclaim_the_Streets

${ }^{10} \mathrm{http} / / / \mathrm{www}$.transitionnetwork.org/

${ }_{11} \mathrm{http}: / /$ www.climatemovement.org.au/groups/

12 http://www.occupytogether.org/
} 
unaddressed challenges (i.e. climate change); political inertia (i.e. the occupy movement); the stories through which neoliberalism sustains itself (i.e. that we are homo economici); neoliberal 'forms of life' such as automobility, and even the home, ${ }^{13}$ among other things. Before examining what an engagement with affective bio-politics might add, it is important to underline that this heterogeneity echoes further recent conceptual developments. Although traditionally many activists have commonly conceived their purpose as being to counter an all-embracing, totalising capitalism whose logic is global in both character and extent (e.g. the 'Multitude' contesting 'Empire'), others have argued for 'neoliberalism as exception' (and exceptions to neoliberalism) (Ong 2006).

Ong’s anthropological study (2006) underlines that neoliberal power rests on its flexibility and ability to hybridise and adopt to 'political settings as varied as postcolonialism, authoritarianism and postsocialism...migrat[ing] from site to site, interacting with various assemblages that cannot be analytically reduced to cases of a uniform global condition of "Neoliberalism" writ large’ (2006, p. 14). Her focus upon East Asia illuminates a range of sites and means that, rather than manifesting a unitary neoliberalism witnessed primarily in a limited number of predictable locations such as banks and corporations, involves a variety of neoliberal logics and governing mechanisms across a wide range of settings, commonly quite unpredictably. Ong's (2006) work might, thus, be understood to suggest that activism should extend its horizons beyond the most evident sites of “"Neoliberalism” writ large’ to the further sites and means in, and through which, neoliberalism is manifest. As outlined above the circumscribed subjectivity underpinning neoliberalism and the 'environmentalities' supporting it provide one such site and are suggestive of means.

McDonald (2006) underlines that the experiential 'grammars of action' he identifies at work in contemporary activism are precisely such a 'means'. His emphasis on the centrality of sense, sensation and embodied experience in contemporary activism underscores both how these disrupt circumscribed neoliberal subjectivity, with its emphasis upon an instrumental individualism opaque to the life of the senses, and point toward new forms of sociality. This occurs through the 'communicative construction of personal experience' (2006, p. 107) that

\footnotetext{
${ }^{13}$ See, for example: http://www.twoaddthree.org/; accessed 25/6/13.
} 
values vulnerability to others and builds relationships through 'embodied intersubjectivity’ (p. 215). While McDonald points to many other important aspects to these 'grammars of action,' such as an altered bodily 'experience of time’ (p. 217), perhaps of greatest significance is how the 'ways of being in the world' that he suggests are manifest in contemporary activism might be understood to prefigure an alternate world. While some suggest a key challenge is to develop 'new stories' better suited to our times (http://dark-mountain.net/about/faqs/; accessed 20/6/13) this emphasis on language and representation risks reproducing the logocentric disregard for embodiment and the senses so central to neoliberal modernity. In this respect McDonald’s (2006) portrayal of contemporary movements as articulating 'ways of being in the world' that counter various of modernity’s pathologies might be understood to articulate a ‘counter-story' using an experiential/corporeal vocabulary illustrative of the substance of the story enunciated.

While McDonald (2006) focuses upon movements, other sites for dissent such as domestic mundanities (see footnote 13) and shopping ${ }^{14}$ have started to gain activist attention with the way 'material grammars' might inform contestationary strategies. This is particularly marked in architecture where a variety of recent work has started to engage the affective and bio-political dimensions of architecture (e.g. Hauptman \& Neidich 2010). Wallenstein’s Biopolitics and the Emergence of Modern Architecture (2009) is the most explicit. ${ }^{15}$ Building, most notably, on Foucault's limited work on architecture Wallenstein argues that the purpose of contemporary architecture is 'to persuade, to prefigure, and to become a project in the sense of pro-jecting that which does not exist, above all a body that senses and feels' (2009, p. 24). Focusing on hospitals he argues in a conventional Foucauldian vein that:

'[r]elations of power and knowledge inform techniques of normalisation, and...produce subjects and objects through the infinite modelling that today extends into the smallest fibers of our bodies and desires' (2009, p. 38).

He is also at pains, however, to underline, echoing Healy’s (2012) contention regarding the design of shopping spaces:

\footnotetext{
${ }^{14}$ For example: http://www.revbilly.com/; accessed 25/6/13.

${ }^{15}$ Sven-Olov Wallenstein, wrote the framing chapter for Hauptman and Neidich (2010). See his website (http://webappl.sh.se/p3/ext/content.nsf/aget?openagent\&key=sh_personal_profil_en_940305; accessed 14/2/13) for further information.
} 
'that the space they create is also an openness, a multiplicity that contains an equally infinite capacity for resistance and transformation, and for the actualisation of other spaces and subjects’ (2009, p. 38).

Architecture and design are thus important sites at which the 'material grammars' involved in affective bio-politics might be engaged. While these have long been recognised to have political content, ${ }^{16}$ the emphasis of this account on affective bio-politics enacted via sensoria gives a quite different take on that politics, underlining that, in addition to explicit considerations such as inclusion and exclusion, it is vital to consider how they shape subjectivities and behaviours.

Finally it is important to address what these observations might offer critics of affective biopolitics of the form adduced here. Barnett (2008) argues that theories articulating the idea that 'a normatively charged threat of harm or injustice' results from subjectification by affective means present the problem of how their normative basis can be judged or 'what reconfigured understanding of criteria might help in this task' (Barnett 2008, p. 198). The account given above suggests a number of such criteria and understandings. McDonald's (2006) emphasis on the experiential, rather than more narrowly cognitive, basis of individual subjectivity and experience of others is a powerful place to start. In the case of the movements, McDonald (2006) focuses on the normative basis for action arising from intersubjective interaction and the understandings that arise from this. This account has also suggested that one such 'understanding' would be to identify particular 'environmentalities,' such as by delineating the sensoria such as shopping malls in which they are manifest, and then, on that basis, developing alternative design principles (Healy 2012) to those currently operative. These would be subject to democratic oversight in the way other normatively infused proposals usually are.

\section{Conclusions}

While a variety of recent work examines the affective dimensions to, and content of, politics and activism little of this has explored affective bio-politics. While others (Anderson 2012) have argued that there are significant affective bio-political dimensions to contemporary neoliberalism this account, building on this author's previous work (Healy 2012), has underlined further,

\footnotetext{
${ }^{16}$ Winston Churchill remarked "[we] shape our dwellings, and afterwards our dwellings shape us" in 1924 (http://www.drmardy.com/chiasmus/masters/churchill.shtml; accessed 18/2/13).
} 
intimate micro-scale dimensions to such politics. Hirschman's (1977/1997) seminal observations regarding the affectively impoverished character of homo economicus provide the basis for the contention that neoliberalism specifically engineers circumstances, such as those of shopping, to lever off of this character (Healy 2012). This argument highlights two key means of contesting neoliberalism. Firstly, the experientially oriented 'grammars of action' that McDonald (2006) detects at work in contemporary movements, which directly address the affectively impoverished character of predominant subjectivities and secondly, the sites at which specific environmentalities, such as those associated with shopping, play out. The latter circumstances are being targeted via the 'material grammars' (McManus 2011) constitutive of them. None of this is straightforward, however, having to contend with neoliberalism's proven flexibility and ability to incorporate, what were once, alternatives. As Wallenstein remarks regarding architecture such means:

'have to come to terms with the control society's dispersive spatialisation... with the forms of subjectification that this spatialisation makes possible...[and]...will always run the risk of prematurely providing an answer before the full weight of the question can be felt' (2009, pp. 40-41).

Wallenstein's remarks underline that, in many ways, such 'answers' are perhaps as much matters of a fundamental cultural project as they are of activism. The sensoria of neoliberalism are the way they are not only because of the forces of capital writ large in corporations, banks and governments, but also because they are manifest in design schools, architectural protocols and the generally taken-for-granted legitimacy of neoliberal imaginaries. In many ways this might be the power of the experiential 'grammars of action' (2006) McDonald detects in contemporary movements. That is that they both demonstrate and instantiate ways of being in the world fundamentally different from, and at odds with, the 'ways' by which the status quo maintains and sustains itself. Of interest, perhaps, here is a widely remarked upswing in societal interest in bodily practices (e.g. Thrift 2000), which suggest a potential broader civil interest in analogous 'grammars.' Whether the case or not, addressing the durability of neoliberalism probably requires that its long-standing ability to colonise the heterogeneity of life, including affective life, requires heterogeneous cross-domain strategies. Here, perhaps, lie some further opportunities. The conjunction of emergent interest in sense, sensibility and embodiment detectable across 
domains as diverse as activism (McDonald 2006), architecture, broader academia and even civil society suggest potential opportunities yet to be explored.

\section{References}

Adey, P. 2008, 'Airports, mobility and the calculative architecture of affective control', Geoforum, vol. 39, pp. 438-451.

Agrawal, A. 2005, Environmentality: technologies of government and the making of subjects, Duke University Press, Durham, NC.

Allen, J. 2006, ‘Ambient power: Berlin’s Potsdamer Platz and the seductive logic of public spaces’, Urban Studies, vol. 43, no. 2, pp. 441-455.

Anderson, B. 2009, 'Affective atmospheres', Emotion, Space and Society, vol. 2, pp. 77-81.

Anderson, B. 2012, 'Affect and biopower: Towards a politics of life', Transactions of the Institute of British Geographers, vol. 37, no. 1, pp. 28-43.

Barnett, C. 2008, 'Political affects in public space: Normative blind-spots in non-representational ontologies,' Transactions of the Institute of British Geographers, vol. 33, pp. 186-200.

Bissell, D. 2010, 'Passenger mobilities: Affective atmospheres and the sociality of public transport’, Environment and Planning D: Society and Space, vol. 28, pp. 270-289.

Brennan, T. 2004, The Transmission of Affect, Cornell University Press, Cornell.

Connolly, W. E. 2002, Neuropolitics: Thinking, Culture, Speed, University of Minnesota Press, Minneapolis MN.

Crowley, J. 2001, 'Convenient comfort: Political economy', in The Invention of Comfort: Sensibilities and Design in Early Modern Britain and Early America, The John Hopkins University Press, Baltimore MA.

Demasio, A.R. 2003, Looking for Spinoza: Joy, Sorrow, and the Feeling Brain, Harcourt, New York.

Duff, C. 2010, 'On the role of affect and practice in the production of place', Environment and Planning D: Society and Space, vol. 28, pp. 881-895.

Gould, D.B. (2002) 'Life during Wartime: Emotions and the development of Act Up', Mobilization: An International Journal, vol. 7, no. 2, pp. 177-200.

Hardt, M. \& Negri, A. 2000, Empire, Harvard University Press, Cambridge MA and London.

Hardt, M. \& Negri, A. 2004, Multitude: War and Democracy in the Age of Empire, Penguin, New York.

Hauptman, D. and Neidich, W. 2010, Cognitive Architecture. From Biopolitics to Noopolitics. Architecture \& Mind in the Age of Communication and Information, 010 Publishers, Rotterdam.

Healy, S. 2010, 'Air-Conditioning and the 'homogenisation' of people and built environments', in Shove, E., Chappells, H. and Lutzenhiser, L. (eds), Comfort in a Lower Carbon Society, Routledge, London and New York, pp. 7-17.

Healy, S. 2012, ‘Atmospheres of consumption: Shopping as Involuntary Vulnerability’, Emotion, 
Space and Society, published online (http://dx.doi.org/10.1016/j.emospa.2012.10.003).

Hirschman, A. O. 1977/1997, The Passions and the Interests: Political Arguments for Capitalism before its Triumph (Twentieth Anniversary Edition), Princeton University Press, Princeton, NJ.

Hynes, M. \& Sharpe, S. 2010, 'Yea-saying laughter', Parallax, vol. 16, no. 3, pp. 44-54.

Hynes, M., Sharpe, S \& Fagan, R. 2007, 'Laughing with the Yes Men: The politics of affirmation’, Continuum, vol. 21, no. 1, pp.107-121.

Hynes, M., Sharpe, S \& Greg, A. 2008, 'Chasing democracy: Dissent, humour and APEC', Social Alternatives, vol. 27, no. 1, pp. 34-38.

Jensen, T. 2011, 'On the emotional terrain of neoliberalism', Journal of Aesthetics and Protest, no. 8 (http://joaap.org/issue8/jensen.htm; accessed 4/2/13).

Kraftl, P. \& Adey, P. 2008, 'Architecture/affect/inhabitation: Geographies of being-in buildings', Annals of the Association of American Geographers, vol. 98, pp. 213-231.

Luke, T. 1995, 'On Environmentality: Geo-power and eco-knowledge in the discourses of contemporary environmentalism', Cultural Critique, no. 31, The Politics of Systems and Environments, Part II, pp. 57-81.

Massumi, B. 2002a, Parables for the Virtual: Movement, Affect, Sensation, Duke University Press, Durham and London.

Massumi, B. 2002b, 'Navigating movements', in Zournazi, M. (ed), Hope: New Philosophies for Change, Lawrence and Wishart, London.

Massumi, B. 2005, 'The future birth of the affective fact', Conference Proceedings: Genealogies of Biopolitics October 2005 (www.radicalempiricism.org; accessed 4/2/13).

Massumi, B. 2009, 'National enterprise emergency: Steps toward an ecology of powers', Theory, Culture \& Society, vol. 26, no. 6, pp. 153-185.

Massumi, B. 2010, 'The future birth of the affective fact: The political ontology of threat', in Gregg, M. and Seigworth, G.J. (eds), The Affect Theory Reader, Duke University Press, Durham and London, pp. 52-70.

Maturana, H. and Varela, F. 1992, The Tree of Knowledge. Biological basis of Human Understanding, Shambhala, Boston, MA.

McDonald, K. 2006, Global Movements: Action and Culture, Blackwell, Malden MA, Oxford and Carlton VIC.

McManus, S. 2011, 'Hope, fear, and the politics of affective agency', Theory \& Event, vol.14, no 4, (DOI: 10.1353/tae.2011.0060; accessed 4/2/13).

Ong, A. 2006, Neoliberalism as Exception: Mutations in Citizenship and Sovereignty, Duke University Press, Durham and London.

Pile, S. 2010, 'Emotions and affect in recent human Geography', Transactions of the Institute of British Geographers, vol. 35, pp. 5-20.

Protevi, J. 2009, Political Affect: Connecting the Social and Somatic. University of Minnesota Press, Minneapolis. 
Ruddick, S. 2010, 'The politics of affect: Spinoza in the work of Negri and Deleuze', Theory, Culture \& Society, vol. 27, no. 4, pp. 21- 45.

Sheller, M. 2004, 'Automotive emotions: Feeling the car', Theory, Culture \& Society, vol. 21, nos. 4/5, pp. 221-242.

Sullivan, L.L. 2005, 'Activism, affect and abuse: Emotional contexts and consequences of the ESF 2004 Organising Process’, Ephemera: theory \& politics in organization, vol. 5, no. 2, pp. 344-369.

Thrift, N. 2000, 'Still life in nearly present time: The object of nature', Body and Society, vol. 6, nos. 3/4, pp. 34-57.

Thrift, N. 2004, 'Intensities of feeling: Towards a spatial politics of affect', Geografiska Annaler, vol. 86 B, no. 1, pp. 57-78.

Torgeson, D. 1999, The Promise of Green Politics: Environmentalism and the Public Sphere, Duke University Press, Durham and London.

Wallenstein, S-O. 2009, Biopolitics and the Emergence of Modern Architecture, Buell Center/FORuM Project and Princeton Architectural Press, New York. 